\title{
EDNRB isoform 3 confers Temozolomide resistance in A375 melanoma cells by modulating membrane potential, reactive oxygen species and mitochondrial $\mathrm{Ca}^{2+}$
}

This article was published in the following Dove Press journal:

Cancer Management and Research

\author{
Yun Shan Chen ${ }^{1}, *$ \\ Fen Liul'* \\ Yi Hong Luo' \\ Yue Fan' \\ Fang Gui Xu' \\ Pin $\mathrm{Li}^{1}$ \\ Bei Zhou' \\ Xiu Yu Pan' \\ Chi Chiu Wang ${ }^{2-4}$ \\ Long Cuil,4 \\ 'Department of Obstetrics and \\ Gynaecology, Guangzhou Women and \\ Children's Medical Center, Guangzhou \\ Medical University, Guangzhou 510623, \\ Guangdong, People's Republic of China; \\ ${ }^{2}$ Reproduction and Development \\ Laboratory, Li Ka Shing Institute of \\ Health Sciences, The Chinese University \\ of Hong Kong, Shatin, Hong Kong; \\ ${ }^{3}$ School of Biomedical Sciences, The \\ Chinese University of Hong Kong, Shatin, \\ Hong Kong; ${ }^{4}$ Department of Obstetrics \\ and Gynaecology, Prince of Wales \\ Hospital, The Chinese University of Hong \\ Kong, Shatin, Hong Kong \\ *These authors contributed equally to \\ this work
}

Correspondence: Long Cui Department of Obstetrics and Gynaecology, Guangzhou Women and Children's Medical Center, Guangzhou

Medical University, 9 Jinsui Rd,

Guangzhou 510623, Guangdong, People's

Republic of China

Tel +86 I 8825063913

Email longcui@link.cuhk.edu.hk
Background: The role of endothelin receptor type B (EDNRB) isoform 3 involved in Temozolomide (TMZ)-induced melanoma cell death has not yet been elucidated.

Methods: The subcellular localization of EDNRB isoform 3 was determined by confocal and immunoblotting assays. Silencing EDNRB isoform 3 was performed by CRISPR/Cas9. Apoptosis was assessed by annexin V/propium iodide staining and caspases 3/7/9 activity. Mitochondrial membrane potential, reactive oxygen species and mitochondrial $\mathrm{Ca}^{2+}$ were measured by flow cytometry. Apoptosis protein array was applied.

Results: Confocal and immunoblot analyses indicate mitochondrial localization of EDNRB isoform 3 and the first $\mathrm{N}$-terminal (1-22) amino acids are sufficient for its mitochondrial targeting. EDNRB isoform 3 depleted A375 cells significantly confers chemoresistance with mitochondrial depolarization, reduced reactive oxygen species, enhanced mitochondrial $\mathrm{Ca}^{2+}$ uptake and decreased caspase 9 activation. Additionally, apoptosis array shows that lack of EDNRB isoform 3 has relatively lower expression of phosphorylation of p53 at S392 and a slightly higher expression of Paraoxonase 2.

Conclusion: Our findings raise the possibility of targeting EDNRB isoform 3 as a new therapeutic strategy in combination with TMZ for melanoma treatment.

Keywords: melanoma, Temozolomide, mitochondrial targeting sequence, apoptosis, reactive oxygen species

\section{Introduction}

Melanoma is the most dangerous form of skin cancer and its incidence is increasing fast. ${ }^{1}$ Five-year survival rates of advanced stage of melanoma are less than $10 \%{ }^{2}$ Temozolomide (TMZ) is one of the alkylating agents used for treatment for metastatic melanoma. However, response rates to TMZ are limited. The widely studied TMZ resistance mechanisms mainly focus on the DNA repair capacity of the cancerous cells such as increased expression of DNA repair protein O6-methylguanine-DNA methyltransferase (MGMT). ${ }^{3}$ In fact, until now, other mechanisms contributing to drug efficacy have been put forward. Investigators have recently shown that TMZ treatment increases reactive oxygen species (ROS) accumulation, induces mitochondrial damage such as mitochondrial depolarization and regulates $\mathrm{Ca}^{2+}$ concentration in human glioma cells or myeloid precursor cells. ${ }^{4-6}$ In this context, mitochondria undergo rapid changes in matrix $\mathrm{Ca}^{2+}$ concentration upon cell stimulation and mitochondrial $\mathrm{Ca}^{2+}$ homeostasis plays an 
important role in maintaining mitochondrial membrane potential. $^{7}$ Thus, mitochondrial membrane depolarization and oxidative stress induced upon TMZ treatment may play an important role in cell death.

Endothelin receptor type $B$ (EDNRB), one of the GPCRs (G protein-coupled receptor) binds with endothelin 3 (EDN3). ${ }^{8}$ This endothelin axis plays an important role in proliferation, differentiation and migration of neural crest cells and melanocyte precursors during embryonic development. ${ }^{9}$ Germline inactivating mutations in either EDNRB/EDN3 signaling are responsible for Waardenburg syndrome. ${ }^{10}$ As a marker of melanoma progression, EDNRB expression is overexpressed in metastatic melanoma. ${ }^{11-13}$ Therefore, blocking EDNRB/EDN3 signaling by an EDNRB antagonist (ie, BQ788) was developed to reduce proliferation of human melanoma in vitro and in vivo. ${ }^{14}$ Although EDNRB blockade by small molecule inhibitors or antibody-drug conjugates was sensitized to apoptosis, ${ }^{15,16}$ these work in a cell-type-dependent manner. $^{17}$ Additionally, EDNRB-specific inhibitor (ie, A192621) shows lack of efficacy in inhibiting the growth of intracranially implanted melanomas in preclinical studies. ${ }^{18}$ Minimal effect is achieved with other EDNRB inhibitors (ie, bosentan) in phase II clinical trials when either given alone or in combination with first-line chemotherapeutic agents. ${ }^{19,20}$ These disappointing results suggest that other mechanisms involving in drug resistance should be well elucidated in the future.

So far, alternatively spliced transcript variants have been described for the $E D N R B$ gene. ${ }^{21-23}$ There are four alternatively spiced forms of $E D N R B$ gene in the databases National Center for Biotechnology Information. EDNRB variant 1 (GenBank: NM_000115.1) and 3 (GenBank: NM_001122659.2) encode EDNRB isoform 1; EDNRB variant 2 (GenBank: NM_003991.3) encodes isoform 2; $E D N R B$ variant 4 (GenBank: NM_001201397.1) encodes $E D N R B$ isoform 3. EDNRB isoform 1 has 442 amino acid residues with a calculated molecular mass of around 49 $\mathrm{kDa}{ }^{22}$ EDNRB isoform 2 has a unique $3^{\prime}$ exon encoding the intracellular C-terminal domain and has 336 amino acid residues with a calculated molecular mass of around $37 \mathrm{kDa}$. It is expressed as a $2.7-\mathrm{kb} \mathrm{mRNA}$ in the lung, placenta, kidney and skeletal muscle. ${ }^{23}$ Tsutsumi et $\mathrm{al}^{24}$ first described the alternative splicing product $E D N R B$ transcript variant $4(\mathrm{EDNRB} \Delta 3)$, which encodes EDNRB isoform 3 with an extra protein sequence of 89 amino acids at the $\mathrm{N}$ terminus comparing EDNRB isoforms 1 and 2. EDNRB isoform 3 has a unique 5' exon encoding
89 amino acids, which has 532 amino acid residues with a calculated molecular mass of $53 \mathrm{kDa}$.

Here, we report at the first time that the EDNRB isoform 3 locates at the mitochondria and play a role in conferring resistance to TMZ-induced apoptosis. Our results provide evidence that depletion of EDNRB isoform 3 protects against mitochondrial depolarization and ROS production via mitochondrial $\mathrm{Ca}^{2+}$ buffering. Thus, we have identified a previously undescribed mechanism by which EDNRB isoform 3 mediates TMZ-induced apoptosis.

\section{Materials and methods Prediction analysis}

The putative transmembrane regions of EDNRB isoform 3 were analyzed by using the PSPORT prediction program. ${ }^{25}$ Two additional bioinformatics software MITOPROT ${ }^{26}$ and TargetP 1.1 server $^{27}$ were also applied to predict MMP for the $\mathrm{N}$ terminal regions of EDNRB isoform 3.

\section{Reagents and antibodies}

Temozolomide (TMZ), staurosporine (STS), etoposide, Ru360, Proteinase K and Luperox ${ }^{\circledR}$ TBH70X, tert-Butyl hydroperoxide solution were purchased from Sigma. Antibodies for EDNRB, GAPDH and HRP-goat anti-rabbit antibody were from Abcam. COXIV antibody was purchased from Santa Cruz Biotechnology. Caspase 9 antibody was supplied from Cell Signaling Technology. Alexa Fluor 488 antibody was from Molecular Probes (Thermo Fisher Scientific).

\section{Cell culture and transfection}

Human embryonic kidney 293 (HEK293) cells and A375 melanoma cells were purchased from ATCC and cultured in growth medium (DMEM) supplemented with $10 \%$ fetal calf serum at $37^{\circ} \mathrm{C}$ under a humidified atmosphere of $5 \% \mathrm{CO}_{2}$. Cells were seeded in culture wells $24 \mathrm{hrs}$ prior to transfection. Wild-type $E D N R B$ variant 4 cDNA (RefSeq: NM_001201397) cloned in a pCMV6 expression vector (pCMV6-EDNRB-v4-GFP) with a variant of green fluorescent protein tag at the C-terminal was described earlier. ${ }^{10}$ The constructed vectors were transfected into HEK293 cells according to the instructions Lipofectamine 2000 reagent (Thermo Fisher Scientific).

\section{Establishment and validation of $\mathrm{A} 375$ EDNRB iso3 -/- \#23 cells}

The sequences of gRNA oligos are shown in Figure 2. It was designed using the CRISPR design tool (crispr.mit.edu) 
and synthesized by Blue Heron Biotechnology, Origene (Bothell, WA, USA). A mixture of $1 \mu \mathrm{g}$ of pCas-Guide vector containing each target gRNA and $1 \mu \mathrm{g}$ of donor DNA was transfected into adherent A375 cells. And then, cells were cultured in medium containing $2.0 \mu \mathrm{g} / \mathrm{mL}$ puromycin for 3 days for selection. Single colonies were selected, and each colony was passaged and genotyped. DNA was isolated using a DNeasy Blood \& Tissue Kit (Qiagen). The genomic region surrounding the CRISPR/ Cas9 target site was PCR amplified and sequenced using a 3100 Genetic Analyzer (ABI). Table S1 shows the primer.

\section{Immunofluorescence staining and confocal microscopy}

The MitoTracker was dissolved in DMSO according to the manufacturer's instructions. A375 cells were stained with Mitotracker Red $\left(50 \mathrm{nM}, 20 \mathrm{mins}, 37^{\circ} \mathrm{C}\right.$, Molecular Probes, Thermo Fisher Scientific) and fixed with 4\% paraformaldehyde according to the manual's instructions. And then, cells were stained with anti-EDNRB primary antibody for $1 \mathrm{hr}$ at room temperature followed by incubation with Alexa Fluor 488 conjugated goat anti-rabbit IgG (Goat anti-Rabbit IgG $(\mathrm{H}+\mathrm{L})$ Secondary Antibody, Alexa Fluor ${ }^{\mathbb{R}} 488$ conjugate). Slides were mounted with Prolong Gold mounting medium (Molecular Probes) and visualized on a Leica SP5 confocal microscope. Alternatively, the plasmids encoding EDNRB isoform 3 fused with EGFP and Mitotracker Red (50 nM, Thermo Fisher Scientific) were co-transfected into HEK293 cells, and the fluorescence of EGFP and Mitotracker Red was observed under the fluorescence microscope.

\section{Mitochondrial isolation and proteinase $\mathrm{K}$ treatment}

Mitochondria were isolated using mitochondrial isolation kit according to the manufacturer's instructions (Thermo Scientific Pierce). Briefly, cells were homogenized in a dounce homogenizer and then centrifuged at $750 \mathrm{~g}$ for 10 mins at $4^{\circ} \mathrm{C}$. The supernatant was further centrifuged at $12,000 \mathrm{~g}$ for $15 \mathrm{mins}$ at $4^{\circ} \mathrm{C}$. The pellet was then washed and kept as the mitochondrial fraction. The supernatant was further centrifuged at $100,000 \mathrm{~g}$ for $1 \mathrm{hr}$ at $4^{\circ} \mathrm{C}$ and designated as the cytosolic fraction. For protease protection assay, $50 \mu \mathrm{g}$ of mitochondrial or cytosolic protein from A375 cells were treated with $50 \mu \mathrm{g} / \mathrm{mL}$ proteinase- $\mathrm{K}$ for 20 mins or 30 mins on ice. Then, proteolysis was halted by the addition of phenylmethylsulfonyl fluoride to a final concentration of $2 \mathrm{mM}$ for 10 mins on ice.
Flow cytometry analysis of cell apoptosis using annexin V-FITC/propidium iodide (PI) staining

Cells were either kept untreated or exposed to cisplatin for indicated time before analysis by flow cytometry. The detection was performed according to the manual of Alexa Fluor ${ }^{\mathbb{R}}$ 488 Annexin V/Dead Cell Apoptosis Kit (Thermo Fisher Scientific). About $1 \times 10^{6}$ cells were collected, washed with ice-cold PBS, and resuspended in binding buffer containing a suitable amount of annexin V-FITC. After 15 mins of incubation in the dark at room temperature, the buffer was removed by centrifugation. The cells were then resuspended in reaction buffer containing PI. Flow cytometry analysis was performed immediately to detect apoptosis.

\section{Protein extraction and western blotting}

Total protein was extracted with RIPA lysis buffer containing $1 \%$ protease inhibitor cocktail (Abcam). Twenty micrograms of protein from mitochondria or whole cell lysates were subjected to sodium dodecyl sulfate-polyacrylamide gel electrophoresis (SDS-PAGE). Proteins were separated on a $10 \%$ separating gel and 3\% stacking gel in the presence of $0.1 \%$ SDS and transferred to polyvinylidene difluoride (PVDF) membranes (Millipore). Blocking for $1 \mathrm{hr}$ was at room temperature with $5 \%$ non-fat milk. The membrane was incubated overnight with the primary antibodies (dilution ratio 1:1000) at $4{ }^{\circ} \mathrm{C}$ with at room temperature, including EDNRB, COXIV and caspase-9 at a 1:1000 dilution in non-fat milk in TBS-T overnight at $4{ }^{\circ} \mathrm{C}$. The membrane was then washed 4 times in TBS-T and incubated with HRP-Goat Anti-rabbit secondary antibody (Abcam) at a 1:7500 dilution in non-fat milk in TBS-T for $1 \mathrm{hr}$ at $37^{\circ} \mathrm{C}$. The membrane was reacted with enhanced chemiluminescent reagents (ECL plus, GE Healthcare) and bands were visualized by an ECL Advance Western Blotting Detection Kit (Amersham).

\section{Evaluation of functional mitochondria}

The mitochondrial membrane potential $(\Delta \Psi \mathrm{m})$ was detected according to the manual of the MitoProbe ${ }^{\mathrm{TM}} \mathrm{JC}-1$ Assay Kit and TMRE (Thermo Fisher Scientific). Briefly, cells suspended in $1 \mathrm{~mL}$ PBS at approximately $1 \times 10^{6}$ cells $/ \mathrm{mL}$ were incubated with $2 \mu \mathrm{M}$ of JC- 1 for 15 mins at $37^{\circ} \mathrm{C}$. The cells were washed and resuspended in $500 \mu \mathrm{L}$ PBS and then analyzed on a flow cytometer with $488 \mathrm{~nm}$ excitation and emission at $590 \mathrm{~nm}$ (red) and $540 \mathrm{~nm}$ (green). At high mitochondrial membrane potentials, JC-1 accumulates in the mitochondria and forms $\mathrm{J}$ aggregates that show a red 
fluorescence emission at $590 \mathrm{~nm}$. mROS production was determined by 10 -min staining of cells with $5 \mathrm{uM}$ MitoSox Red. All samples were examined by flow cytometry analysis using Cytomics FC 500 (Beckman Coulter) flow cytometer.

\section{Mitochondrial calcium measurement}

Mitochondrial calcium level was determined using calcium-sensitive dye Rhod2-AM (excitation wavelength, $552 \mathrm{~nm}$; emission wavelength, $581 \mathrm{~nm}$ ). The fluorescent dye Rhod2-AM has a net positive charge, facilitating its sequestration into mitochondria through membrane potential-driven uptake. ${ }^{28}$ According to the instructions, cells were harvested, pelleted and resuspended in ice-cold PBS and $10 \mu \mathrm{M}$ Rhod2-AM. And then cells were stained with Rhod-2 AM (Thermo Fisher Scientific) for $1 \mathrm{hr}$ at $37^{\circ} \mathrm{C}$. Mitochondrial calcium levels were determined by Cytomics FC 500 (Beckman Coulter) flow cytometer.

\section{Protein array}

After treatment with $\mathrm{TMZ}$ for $24 \mathrm{hrs}$, the cells were harvested for analysis of apoptosis protein expression. The Proteome ProfilerTM Human Apoptosis array kit (ARY009; R\&D Systems) was used to detect the relative expression levels of 35 apoptosis-related proteins according to the manufacturer's instructions. Briefly, $\sim 1 \times 10^{7}$ cells were solubilized in lysis buffer provided by the manufacturer. The recommended quantity of lysates was diluted and pipetted onto the membranes and incubated overnight at $2-8^{\circ} \mathrm{C}$ on a rocking platform shaker. Biotinylated secondary antibody cocktail provided by the manufacturer was pipetted onto membranes and incubated for $1 \mathrm{hr}$. After the washing process, the membranes were incubated with streptavidin-HRP provided by the manufacturer for $30 \mathrm{mins}$. The signals were developed using chemiluminescent reagents and then exposed to X-ray films. The positive signals were analyzed using ImageJ software.

\section{Results}

\section{Prediction analysis}

Results of the PSPORT prediction analysis suggested that human EDNRB isoform 3 (EDNRB isoform 3, 532 amino acids) had a putative recognition site (SRI $\mid$ WG between the amino acid residues 113-117 of EDNRB isoform 3) of mitochondrial potential peptide (MPP) (R-2 motif, XRX | $\mathrm{X}(\mathrm{S} / \mathrm{X}))^{25}$ Two additional bioinformatics software MITOPROT $^{29}$ and TargetP 1.1 server $^{27}$ were used to predict the subcellular location of eukaryotic proteins. TargetP 1.1 prediction gave a score of 0.817 for the presence of a mitochondrial targeting peptide (MTP) in EDNRB isoform 3 . The MitoProt II v1.101 revealed that EDNRB isoform 3 has a $92.41 \%$ probability of being exported to the mitochondria.

Both programs predicted that there are 115 residues long mitochondria targeting peptide in the $\mathrm{N}$ terminal of EDNRB isoform 3, indicating that its cleavage site for mature peptide was located between 115 and 116 residues.

\section{The $\mathrm{N}$ terminus of EDNRB isoform 3 promotes mitochondrial localization}

Based on multiple subcellular localization prediction algorithms, it appears that EDNRB isoform 3 contains a mitochondrial targeting sequence (MTS) at the $\mathrm{N}$ terminus (Figure 1A). To determine if endogenous EDNRB isoform 3 is localized to the mitochondria, confocal microscopy experiment has been conducted. The fluorescence experiment results showed that the full-length EDNRB isoform 3 colocalized with mitochondria that were stained with MitoTracker Red in A375 melanoma cells (Figure 1B). Additionally, western blotting of isolated cytosolic and mitochondrial fractions revealed that EDNRB isoform 3 was present in the mitochondrial fraction with a molecular weight of around $40 \mathrm{kDa}$ (Figure 1C). The immunoblots also detected EDNRB isoform 1 in the cytosolic extract, which showed two bands with a molecular weight around 50 and $70 \mathrm{kDa}$.

In order to determine the minimal region required for mitochondrial targeting on protein distribution in the cell, PSIPRED server ${ }^{30}$ was applied to predict the secondary structure. The results found that the first 1-22 residues of EDNRB isoform 3 contained a positively charged amphipathic $\alpha$-helix (Figure S1, residues 1519 ), indicating that it may serve as a signal sequence for matrix transport. To confirm that the first 1-22 residues of EDNRB isoform $3 \mathrm{~N}$ terminus is sufficient for its transportation to mitochondria, we then analyzed the cellular localization of fusion proteins composed of the $\mathrm{N}$ terminus of EDNRB isoform 3 attaching to a fluorescent protein. We had previously found that HEK293 cells were the preferred model for this study because of lack of endogenous EDNRB isoform 3 expression and also because of its high transfection efficiency. ${ }^{10}$ As shown in Figure 1B, the first 1-22 residues of EDNRB isoform 3-C terminus-EGFP colocalized very well with that of the Mito Tracker Red dye. 


\section{A}

\section{EDNRB isoform 3}

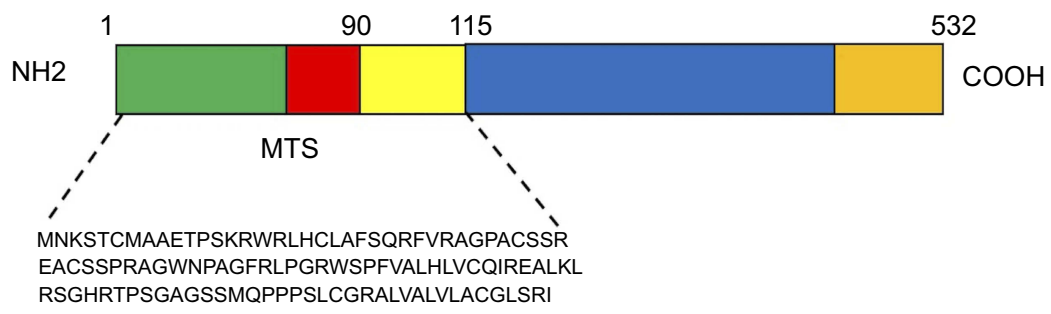

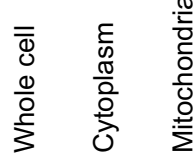
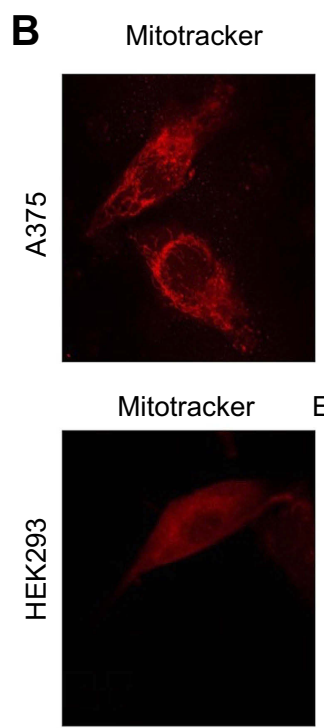

EDNRB isoform 3

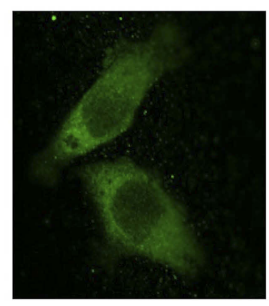

EDNRB isoform 3-GFP

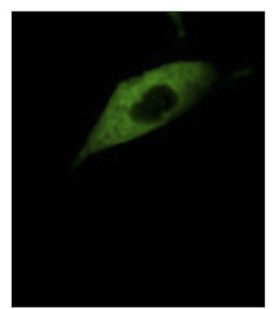

Merge
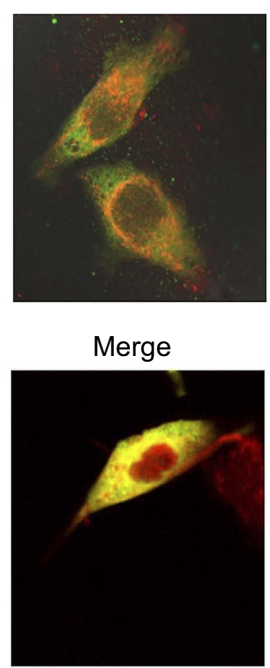

C

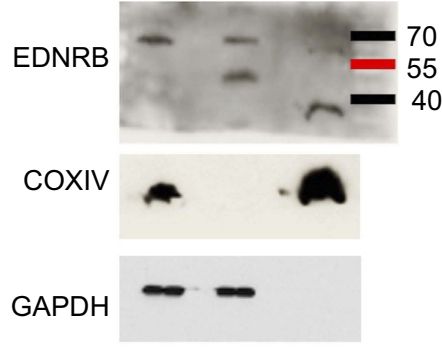

D

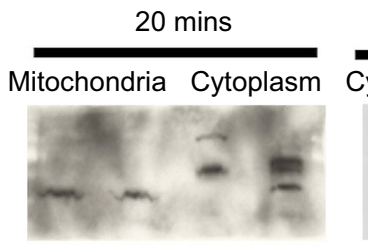

Proteinase K $(50 \mu \mathrm{g} / \mathrm{ml})$

Figure I EDNRB isoform 3 is targeted to mitochondria. (A) EDNRB isoform 3 was predicted to contain a mitochondrial targeting sequence at the $\mathrm{N}$ terminus using Mitoprot and iPSORT. (B) Endogenous EDNBR and transiently expressed EDNRB isoform 3-GFP colocalizes with mitochondria in A375 and HEK293 cells. (C). Mitochondria were stained using Mitotracker Red and visualized under confocal microscopy. (C) Subcellular distribution of EDNRB isoform 3 by western blot. Membrane was probed with EDNRB C terminus antibody (abl I7529), which detected a $\sim 40 \mathrm{kDa}$ band in mitochondrial extract. GAPDH and COXIV were used as markers for the cytosolic and mitochondrial fractions, respectively. (D) Mitochondrial or cytosolic fractions were treated with the indicated concentrations of proteinase $\mathrm{K}$ and analyzed by immunoblotting.

To determine whether EDNRB isoform 3 is associated with the outer membrane, purified intact mitochondria were treated with proteinase $\mathrm{K}$ for various length of time. As shown in Figure 1D, EDNRB isoform 3 was protease-insensitive under these conditions, indicating that it is not associated with the outer membrane and is present within the mitochondria. In contrast, EDNRB isoform 1 located in the cell plasma membrane was rapidly degraded.

We thus conclude that only the EDNRB isoform 3 can facilitate targeting to mitochondria in a cellular environment and the first 22 amino acid acids in the $\mathrm{N}$-terminus of EDNRB isoform 3 have a mitochondrial targeting ability comparable to that of the full-length EDNRB isoform 3.

\section{Depletion of EDNRB isoform 3 confers resistance to alkylating agents}

To determine whether EDNRB isoform 3 plays a role in modulating sensitivity to DNA-damaging agents, we generated A375 melanoma cells that were stably depleted of the EDNRB isoform 3 protein using CRISPR/Cas9 technology through targeting EDNRB isoform 3-specific mRNA transcript region (Figure 2A). Sequence analysis of the PCR product revealed that homologous donor sequence was successfully integrated into wild-type genomic region of EDNRB isoform 3 (Figure 2B), representing EDNRB isoform 3 knockout A375 cells (referred as EDNRB iso3 -/- \#23).

The data from the flow cytometric apoptosis assay showed that increased annexin $\mathrm{V}$ positive cells in the 
A
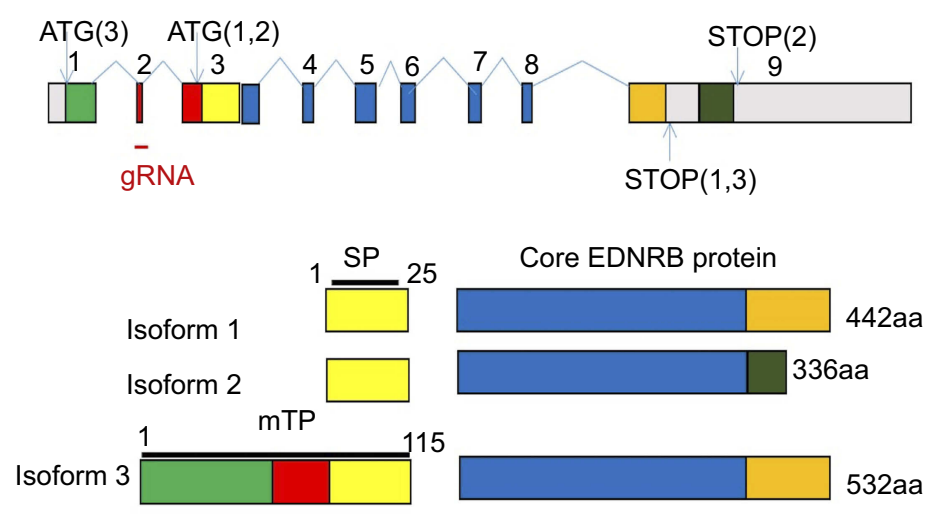

Correct integration of GFP-puro cassette

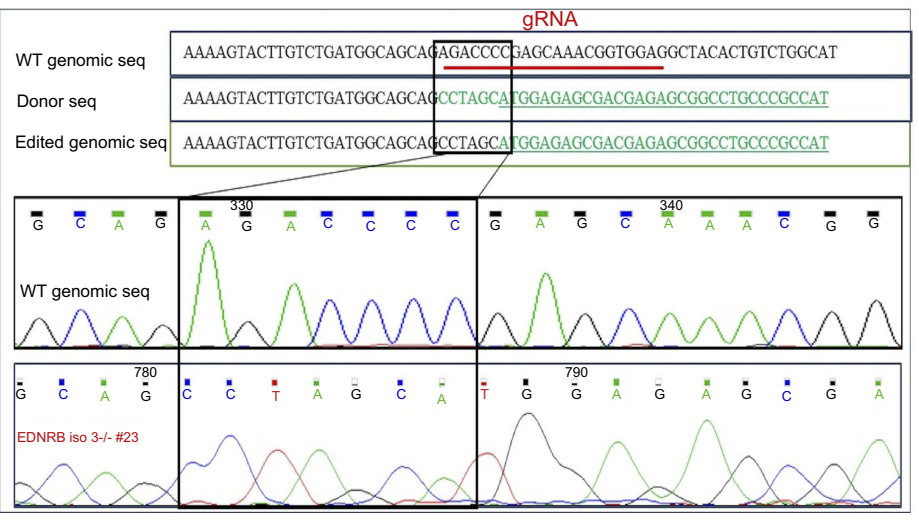

B

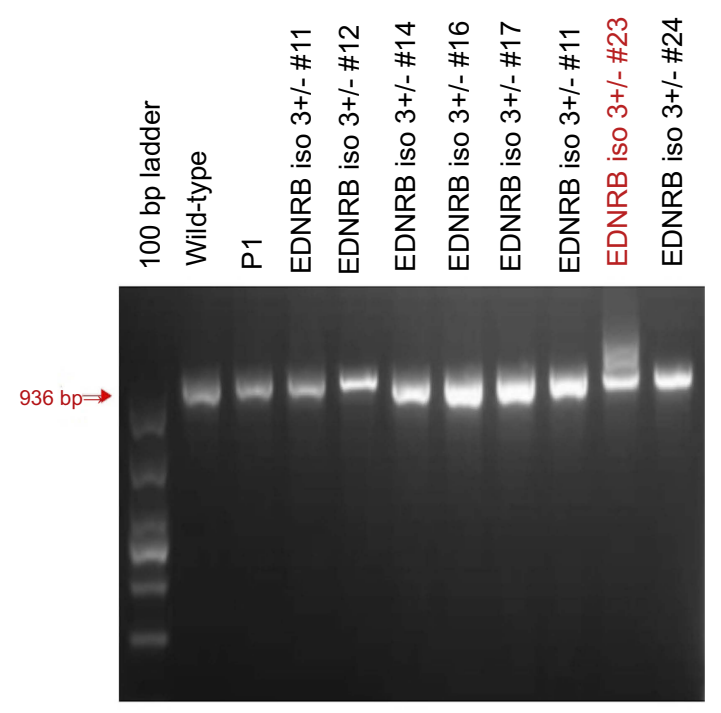

Figure 2 Establishment and validation of A375 EDNRB iso3 -/- \#23 cells. (A) Schematic representation of the EDNRB genomic region. There are three alternatively spliced isoforms. EDNRB isoform I has 442 amino acid residues. EDNRB isoform 2 has 336 amino acid residues with a unique $3^{\prime}$ exon encoding the intracellular C-terminal domain. EDNRB isoform 3 has a unique $5^{\prime}$ exon encoding 89 amino acids, which has 532 amino acid residues. Red line indicates gRNA primer position. (B) The 936 bp length of fragment surrounding the edited part was amplified and the amplicons from each puromycin-resistant colonies were separated in agarose gels. EDNRB isoform 3 -/-\#23 cells contains integrated the GFP-puromycin cassette as the figure shown.

Abbreviations: SP, signal peptide; mTP, mitochondrial targeting peptide; WT, wild-type.

A375 control cells in the presence of TMZ treatment compared with EDNRB isoform 3-depleted A375 cells $(p<0.0001$, Figure $3 \mathrm{~A}$ and $\mathrm{B})$. Consistent with annexin $\mathrm{V}$ staining data, significant increased caspase $3 / 7$ activation was found in A375 control cells (Figure 3C). Furthermore, caspase-9 activation was determined by Western blot. As shown in Figure 3D, caspase-9 was cleaved to yield more fragment following TMZ treatment in A375 control cells compared with EDNRB isoform 3-depleted A375 cells.

To determine whether the resistant phenotype of EDNRB isoform 3-depleted cells was specific to TMZ, we treated control and EDNRB isoform 3-depleted cells with DNA-damaging agents known to induce apoptosis in A375 cells; namely, etoposide, STS and TBH70X. In contrast to being resistant to alkylation-induced apoptosis. EDNRB isoform 3-depleted cells underwent levels of apoptosis similar to those of control cells after treatment with either UV, etoposide, STS or TBH70X as judged by caspase activation (Figure 3C-D). Collectively, these results show that depletion of EDNRB isoform 3 confers resistance to TMZ but not other DNA-damaging agents.

\section{EDNRB isoform 3 plays a key role in mitochondrial dysfunction leading to TMZ-induced apoptosis}

To investigate whether EDNRB isoform 3 plays a role in the initiation of mitochondrial dysfunction that was induced by $\mathrm{TMZ}$, we analyzed the characteristics of mitochondrial damage, such as mitochondrial depolarization and formation of reactive oxygen species (ROS). We measured mitochondrial membrane potential $(\Delta \Psi \mathrm{m})$ using two different types of membrane potential 


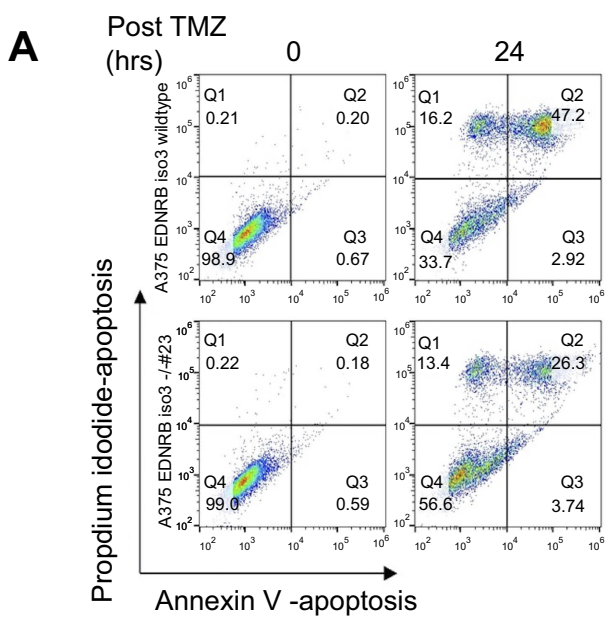

B

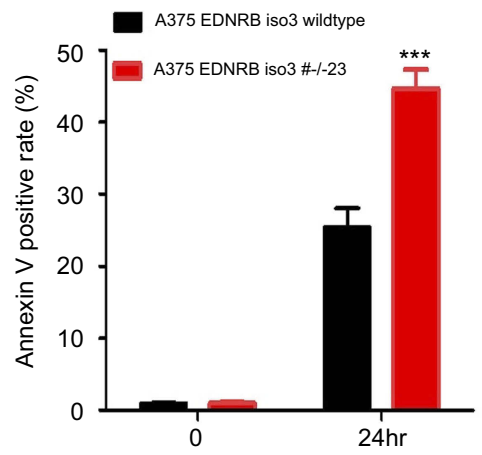

C Caspase $3 / 7$ activity

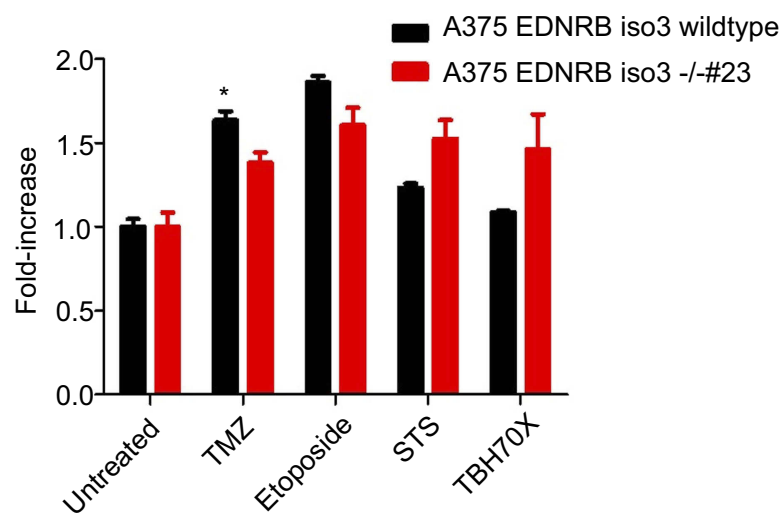

D

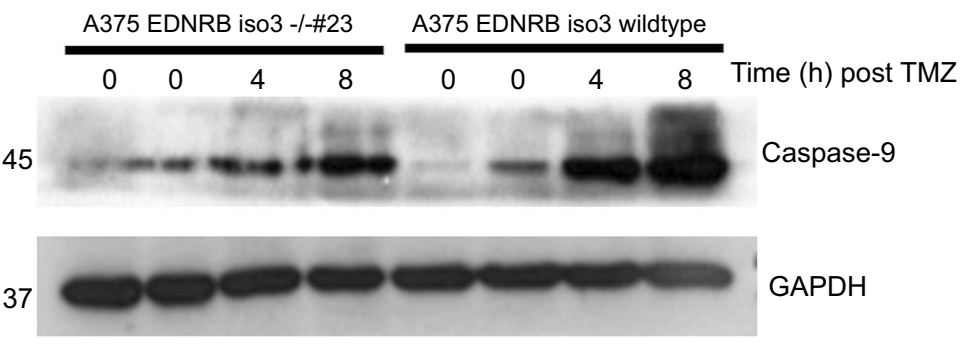

Figure 3 Depletion of EDNRB isoform 3 attenuates TMZ-induced apoptosis in A375 cells. (A) Apoptosis was analyzed by flow cytometry after annexin $V$ and propidium iodide staining. Cells were incubated with and without TMZ (I.5 mM) for $24 \mathrm{hrs}$. (B) Total apoptosis is the sum of the percentage of annexin $\mathrm{V}$ only and annexin V/propidium iodide stained cells. Data represent as mean \pm SD from three independent experiments. $* * * p<0.00 \mathrm{I}$. (C) Caspase $3 / 7$ activation in A375 cells after treatment with the indicated agents. ${ }^{*} p<0.05$. (D) Immunoblot analysis of active caspase 9 after exposure to TMZ for indicated time.

indicators: JC-1 and tetramethylrhodamine (TMRE). A significant depolarization of mitochondria was observed at $24 \mathrm{hrs}$ as measured by JC-1 staining after treatment with $1.5 \mathrm{mM} \mathrm{TMZ}$ for $24 \mathrm{hrs}$ (Figure $4 \mathrm{~A}$ and B). Similarly, an overall decrease in TMRE staining in TMZ-treated A375 control cells following TMZ treatment, indicating the loss of mitochondrial $(\Delta \Psi \mathrm{m})$ after TMZ treatment (Figure 4C and D). Consistent with the maintenance of mitochondrial function, EDNRB isoform 3-depleted cells did not exhibit a significant increase in ROS after TMZ treatment, as measured using MitoSox Red, a mitochondrial-targeted form of the superoxide indicator dihydroethidium (Figure 4E and F). Collectively, these results indicate that loss of EDNRB isoform 3 is involved in cell death induced by mitochondrial membrane potential or/and ROS.

\section{Lack of EDNRB isoform 3 results in elevated mitochondrial $\mathrm{Ca}^{2+}$ levels during TMZ-induced apoptosis}

Mitochondrial inner membrane voltage $(\Delta \Psi \mathrm{m})$ mainly promotes mitochondrial $\mathrm{Ca}^{2+}$ uptake, which is maintained by the electron transport chain and oxidative phosphorylation. $^{31}$ To determine whether TMZ-induced mitochondrial depolarization is suppressed by depletion of EDNRB isoform 3 in cells, we monitored $\mathrm{Ca}^{2+}$ influx into mitochondria using mitochondrial probe Rhod2AM. ${ }^{32}$ After TMZ treatment, EDNRB isoform 3-depleted A375 cells showed a marked increase in Rhod2 fluorescence intensity, but control A375 cells showed only a slight increase (Figure 5A and B). Ru360, an inhibitor of the mitochondrial calcium uniporter, was used to confirm 


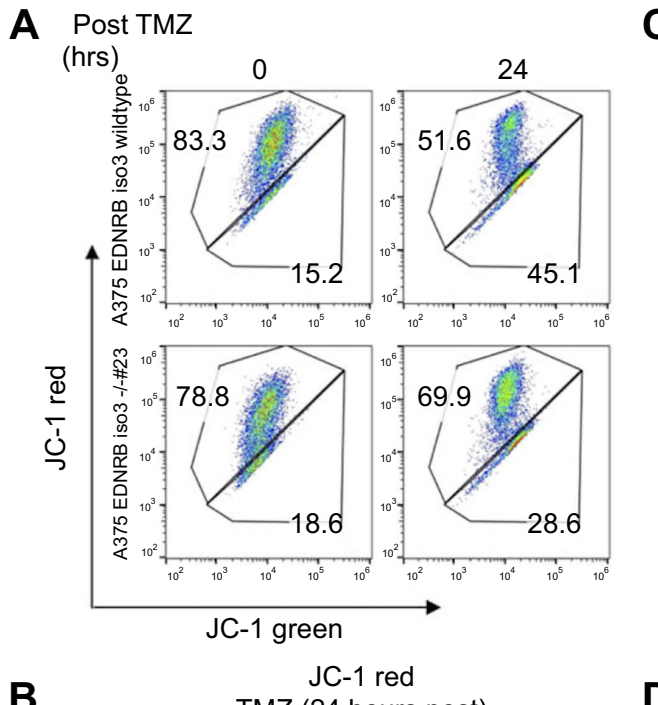

B

$$
\text { TMZ (24 hours post) }
$$

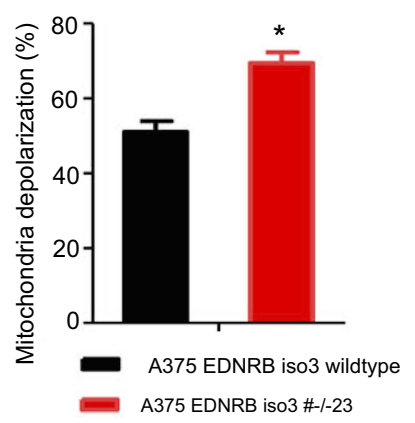

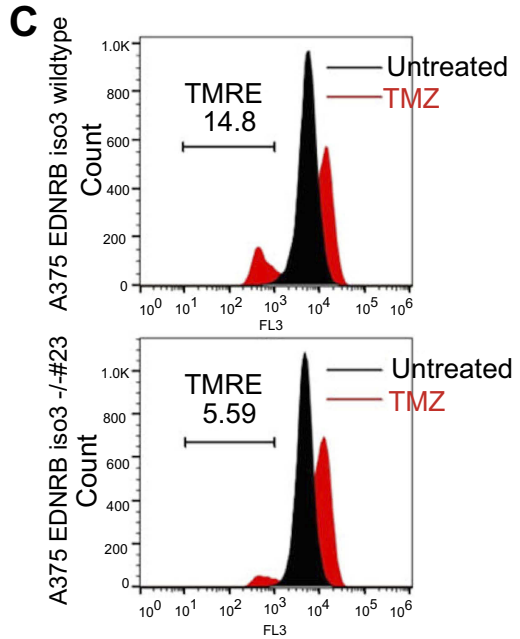

D

$\triangle \Psi \mathrm{m}$ TMZ (24 hours post)

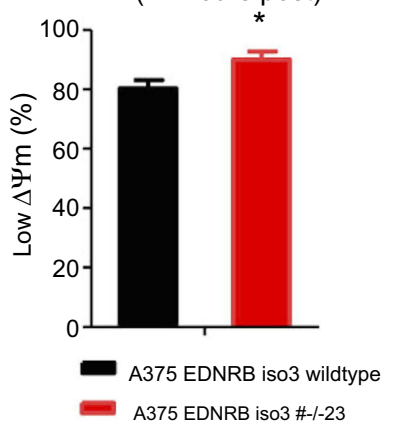

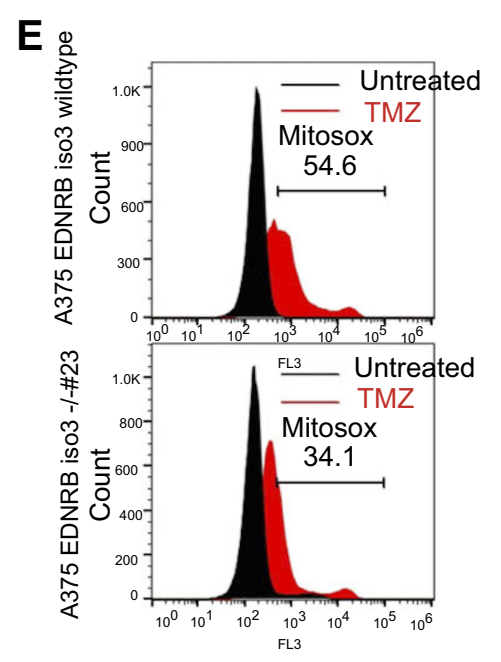

$\mathbf{F}$

ROS formation TMZ (24 hours post)

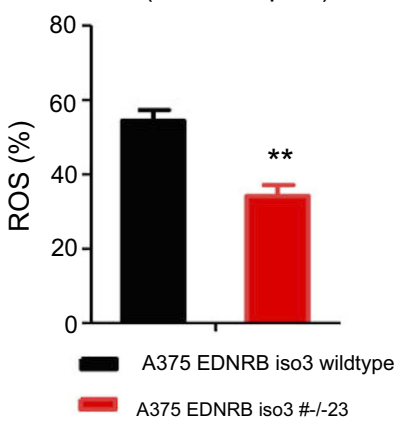

Figure 4 Resistance of EDNRB isoform 3-depleted cells to TMZ that accompanied lower mitochondrial depolarization and reduced formation of ROS. (A) Scatter plots of JC-I staining for mitochondria membrane potential as measured through JC-I staining. (B) Quantification of cells with depolarized mitochondria as monitored by JC-I red fluorescence intensities. (C) Representative flow cytometry plot of untreated and TMZ-treated cells stained with TMRE to monitor mitochondria membrane potential $(\Delta \Psi \mathrm{m})$. (D) Percentage of cells with low TMRE staining, indicative of reduced mitochondrial $\Delta \Psi \mathrm{m}$ after treatment with TMZ. (E) Quantification of ROS formation by mitochondrial superoxide indicator MitoSox Red. (F) Percentage of cells with increased MitoSox fluorescence intensities indicating high levels of ROS. Bars for all graphs represent the mean of at least three independent experiments. ${ }^{*} p<0.05 ;{ }^{*} p<0.01$.

A

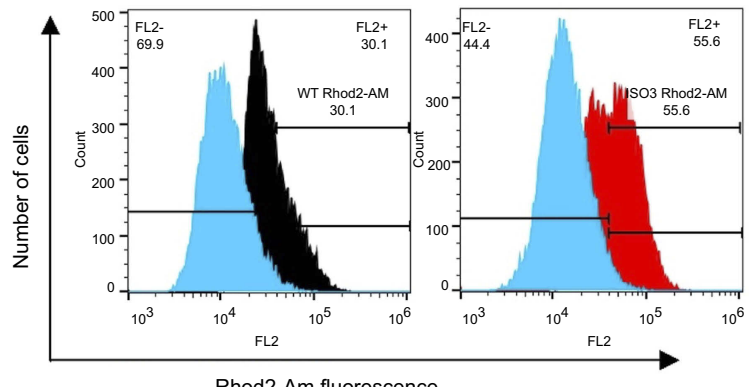

B $\quad$ Rhod2AM $\quad$ C

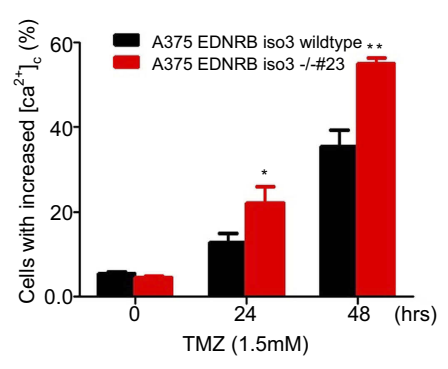

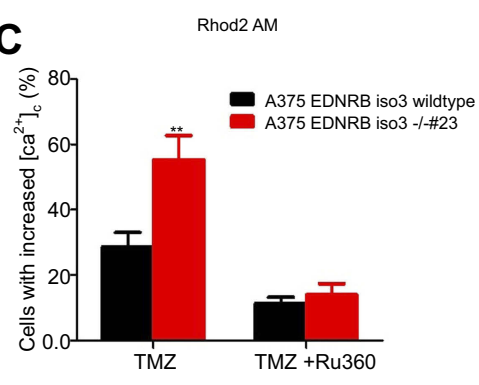

Figure 5 Depletion of EDNRB isoform 3 induced increase in mitochondrial $\mathrm{Ca}^{2+}$ concentration. (A) Representative flow cytometry histograms indicating Rhod2-AM staining signals of EDNRB isoform 3-depleted and control A375 cells after treated with $1.5 \mathrm{mM}$ TMZ for 24 and 48 hrs. Rhod2 fluorescence intensity was monitored by flow cytometry. (B) The percentages of Rhod2 fluorescence cells are shown for three experimental conditions (mean \pm SD). (C) Rhod2 fluorescence intensities were also assessed in the presence of I mM Ru360. ${ }^{*}<<0.05 ;{ }^{*} p<0.01$.

these results (Figure 5C). In addition, we also examined the effect of EDNRB isoform 3 on cell death induced by A23187, a $\mathrm{Ca}^{2+}$ ionophore. EDNRB isoform 3-depleted cells showed significant resistance to A23187-induced cell death (Figure S2). These results indicate that compared to control cells, EDNRB isoform 3-depleted cells 
absorb a larger amount of $\mathrm{Ca}^{2+}$ into their mitochondria without loss of mitochondrial depolarization.

\section{EDNRB isoform 3-mediated apoptosis may be related to reduced expression of phosphorylation of p53 at S392}

To evaluate the effects of EDNRB isoform 3 depletion on alterations of apoptosis protein expression under TMZ treatment, Proteome Profiler ${ }^{\mathrm{TM}}$ Human Apoptosis array was performed. TMZ-mediated protein expressions were assessed in the EDNRB isoform 3-depleted A375 cells compared to the A375 control cells. Of the 35 apoptosis-related proteins on the array, we found that TMZ-treated A375 control cells showed upregulated expression of 2 pro-apoptosis proteins, Bid and Pro-Caspase-3, compared to EDNRB isoform 3depleted A375 cells (Figure 6A and B). On the other hand, the anti-apoptotic proteins such as Bcl-2 were not significantly altered. Additionally, EDNRB isoform 3 depletion also downregulated the protein expression of Phospho-p53 (S392) and upregulated Paraoxonase 2 (PON2) (Figure 6A and B). Phosphorylation of p53 at S392 is correlated with increased DNA binding ${ }^{33,34}$ and PON2 located in mitochondria inhibits mitochondrial superoxide formation. ${ }^{35}$ These results may suggest that changes of these proteins were necessary for ENDRB isoform 3 protection of cell apoptosis induced by TMZ.

\section{Discussion}

Three EDNRB isoforms have been described, EDNRB isoform 1, 2 and 3, which are encoded by a single mammalian EDNRB gene and differ in their $\mathrm{N}$ or $\mathrm{C}$-terminal sequences due to alternative splicing. ${ }^{24} \mathrm{~N}$ terminus of the isoform 1 or 2 serves as a signal peptide for $\mathrm{N}$ tail translocation and consequently for a functional receptor in the cell membrane, ${ }^{36}$ but no function has been studied for the $\mathrm{N}$ terminal of isoform 3. For the past years, several $\mathrm{G}$ proteins previously characterized as regulators working at the plasma membrane have been recently identified as translocating to mitochondria. ${ }^{37-39}$ In this study, bioinformatics analysis showed that $\mathrm{N}$ terminal of isoforms 3 contained MTS, which enriches of specific aa and the ability to form amphiphilic $\alpha$-helices. ${ }^{40}$ As expected, the immunoblots and confocal experiments confirmed its localization in mitochondria. Since no isoform 3 specific antibody is accessible, we detected two double bands in cytosolic parts using EDNRB C terminus antibody, which is consistent with previous findings. The two bands represent EDNRB isoform 1 after proteolytic cleavage at Arg64 and Ser65 sites of N extracellular terminus and full-length receptor, respectively. ${ }^{10,41,42}$ The proteolytic cleavage at Arg64 and Ser65 may allegedly be due to the metal proteinases released during the preparation of membrane fractions. ${ }^{42,43}$ Mitochondrial transport systems import proteins that contain different types of localization signals, but most matrix proteins contain an N-terminal sorting signal, which is often proteolytically removed during the import. ${ }^{44}$ This explains the molecular weight of EDNRB isoform 3 that was smaller than estimated.

Tsutsumi et $\mathrm{al}^{24}$ showed that EDNRB isoform 3 was expressed in human gut tissue. But little was reported on its function. A previous study described a missense heterozygous mutation $\mathrm{K} 15 \mathrm{X}$ in EDNRB isoform 3 in a sporadic Caucasian HSCR (Hirschsprung's disease) patient. ${ }^{45}$ It implies that this kind of isoform is crucial for the survival of neural crest cells. Additionally, it has been reported that
A

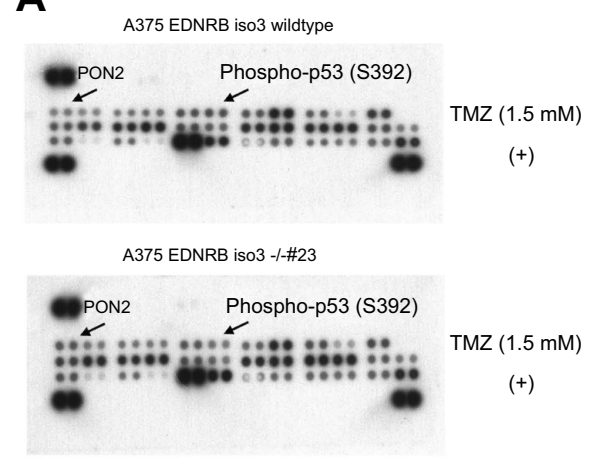

B

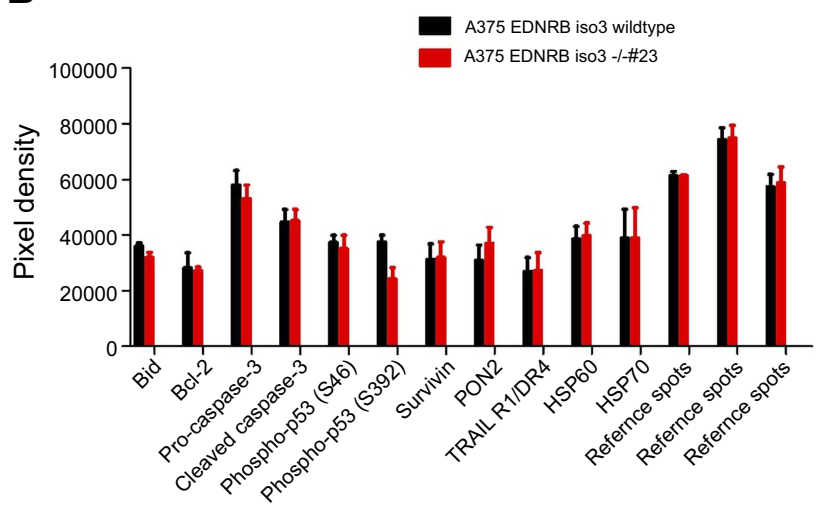

Figure 6 Effects of depletion of EDNRB isoform 3 on the expression of apoptosis signaling pathway proteins in A375 cells. (A) Results of apoptosis protein array analysis using EDNRB isoform 3-depleted and control A375 cells treated with TMZ for 24 hrs. (B) Quantitative analysis of the protein array shown in (A). 
repression of GPCRs expression sensitizes cells to DNA damage or ischemic hypoxia-induced apoptosis. ${ }^{46,47}$ As one of the members of GPCRs, we asked whether this isoform has similar functions. We next generated ENDRB isoform 3-depleted A375 melanoma cells, which was proved to contain both isoform 1 and 3 in our lab. Our results showed a correlation between EDNRB isoform 3 silencing and $\mathrm{TMZ}$ resistance, but not other apoptosis inducers such as STS, etoposide and TBH70X, indicating that EDNRB isoform 3 is involved in alkylating agents induced cell death. We found that lack of EDNRB isoform 3 markedly decreased the activity of caspase 9, indicating intrinsic mitochondrial apoptosis pathway was activated. Caspase 9 activation may further lead to its downstream caspase 3 cleavage which can activate its substrates such as PARP, resulting in activation of DNA fragmentation of apoptosis. $^{48}$ As mentioned earlier, production of mitochondrial depolarization and reactive oxygen species is found in TMZ-induced apoptosis. ${ }^{6}$ In the present study, compared with control cells, EDNRB isoform 3-depleted cells demonstrated a robust $\Delta \Psi \mathrm{m}$ as evidenced by $\mathrm{JC}-1$ and TMRE staining. Consistent with the maintenance of mitochondrial function, EDNRB isoform 3-depleted cells exhibited a slight increase in ROS after TMZ treatment. The maintenance of mitochondrial function most likely explains relatively lower ROS accumulation in EDNRB isoform 3-depleted cells. Loss of $\Delta \Psi \mathrm{m}$ also leads to the release of pro-apoptotic factors such as cytochrome c. ${ }^{49}$ The mechanism of EDNRB isoform 3 mediates TMZ resistance such as cytochrome c release, remains to be elucidated.

It has been reported that GPCRs modulate $\mathrm{Ca}^{2+}$ homeostasis and/or $\mathrm{Ca}^{2+}$ signals and are known to regulate cell proliferation, migration and survival. ${ }^{39,50-52}$ Some of the GPCRs have been recently found localized on mitochondria regulating mitochondrial function. ${ }^{39,53}$ Mitochondria is the primary subcellular $\mathrm{Ca}^{2+}$ store buffering cytosolic $\mathrm{Ca}^{2+} \cdot 54$ Our results indicated that EDNRN isoform 3-depleted mitochondria accumulated excess $\mathrm{Ca}^{2+}$ without significant loss of $\Delta \Psi \mathrm{m}$ and generation of high levels of ROS following treatment with TMZ. Moreover, upon A23187 treatment EDNRB isoform 3-depleted A375 melanoma cells accumulated more $\mathrm{Ca}^{2+}$ than wild-type A375 melanoma cells and were significantly more resistant to A23187-induced death, as measured by Annexin $\mathrm{V}$ staining. Thus, these results demonstrated that mitochondrial $\mathrm{Ca}^{2+}$ uptake is strongly accelerated in the absence of EDNRB isoform 3 expression during alkylating agents induced cell death process. There is a controversy conception that $\mathrm{Ca}^{2+}$ overload leads to stimulated ROS generation in mitochondria. The role mitochondrial $\mathrm{Ca}^{2+}$ uptake plays in ROS generation remains largely elusive. Some investigators have found mitochondrial $\mathrm{Ca}^{2+}$ uptake increase in ROS generation, ${ }^{55,56}$ but others have shown it has effect on $^{57}$ or even decreases in ROS generation. ${ }^{58,59}$ In the present study, our findings support a relationship between an increase in mitochondrial $\mathrm{Ca}^{2+}$ absorbing and resistance to cell death following exposure of TMZ in absence of EDNRB isoform 3 expression. Inhibition of mitochondrial $\mathrm{Ca}^{2+}$ uptake by $\mathrm{Ru} 360$ attenuated the effects, confirmatively suggesting that EDNRB isoform 3 plays a direct role in mitochondrial $\mathrm{Ca}^{2+}$ uptake. Collectively, these results we observed imply that the loss of $\Delta \Psi \mathrm{m}$ might be involved in cell death due to $\mathrm{Ca}^{2+}$ overload and accumulation of ROS. A further understanding about new functions of EDNRB isoform 3 in manipulating mitochondrial $\mathrm{Ca}^{2+}$ uptake and thus provides a new target for regulation of $\mathrm{Ca}^{2+}$ signaling related to cell survival and death.

Previous report revealed that one of GPCRs regulated apoptosis induced by DNA damage through modulate phosphorylation status of p53. ${ }^{60}$ Hyperphosphorylation of p53 under genotoxic stress was found to result in both p53 stabilization and activation. We obtained a similar result that the TMZ treatment resulted in decreased phosphorylation at serine residues 392 on p53 EDNRB isoform 3depleted A375 cells than in A375 control cells. Phosphorylation of S392 in p53 enhanced DNA binding through regulating p53 tetramerization. ${ }^{34}$ This result suggests that the status of p53 correlates to TMZ-induced apoptosis in the absence of EDNRB isoform 3. We also found depletion of EDNRB isoform 3 can increase the expression of PON2. PON2 is an antioxidant mitochondrial enzyme, protecting cells from death caused by oxidative stress. ${ }^{61,62}$ The above findings imply that, EDNRB isoform 3 has the ability of mediating generation of ROS may due to stimulation of the expression of PON2.

Taken together, our results suggest that EDNRB isoform 3 participates in resistance against TMZ-induced proapoptotic signals in melanoma cells. Therefore, targeting EDNRB isoform 3 could be an appropriate and beneficial strategy in melanoma management.

\section{Acknowledgments}

The authors would like to thank the National Natural Science Foundation of China (Grant No: 81301827 and 81773291) from State Council in China and Direct Grant 
for Research (2015.1.040) from The Chinese University of Hong Kong for financial support. The abstract of this paper was presented at the American Association for Cancer Research Annual Meeting 2018 named "EDNRB isoform 3 confers temozolomide resistance in human melanoma cells by modulating membrane potential, reactive oxygen species and mitochondrial $\mathrm{Ca}^{2+}$ " as a poster presentation with interim findings. The poster's abstract was published in "Poster Abstracts" in Chicago, IL. Philadelphia (PA): AACR, Cancer Res 2018;78(13 Suppl): Abstract nr 1858: Hyperlink with DOI (http://can cerres.aacrjournals.org/content/78/13_Supplement/1858).

\section{Disclosure}

The authors report no conflicts of interest in this work.

\section{References}

1. Simard EP, Ward EM, Siegel R, Jemal A. Cancers with increasing incidence trends in the United States: 1999 through 2008. CA Cancer J Clin. 2012;62(2):118-128. doi:10.3322/caac.20141

2. Balch CM, Gershenwald JE, Soong SJ, et al. Final version of 2009 AJCC melanoma staging and classification. J Clin Oncol. 2009;27 (36):6199-6206. doi:10.1200/JCO.2009.23.4799

3. Lv JF, Hu L, Zhuo W, Zhang CM, Zhou HH, Fan L. Epigenetic alternations and cancer chemotherapy response. Cancer Chemother Pharmacol. 2016;77(4):673-684. doi:10.1007/s00280-015-2951-0

4. Lin CJ, Lee CC, Shih YL, et al. Resveratrol enhances the therapeutic effect of temozolomide against malignant glioma in vitro and in vivo by inhibiting autophagy. Free Radic Biol Med. 2012;52(2):377-391. doi:10.1016/j.freeradbiomed.2011.10.487

5. Lin CJ, Lee CC, Shih YL, et al. Inhibition of mitochondria- and endoplasmic reticulum stress-mediated autophagy augments temozolomide-induced apoptosis in glioma cells. PLoS One. 2012;7(6): e38706. doi:10.1371/journal.pone.0038706

6. Wang H, Cai S, Ernstberger A, et al. Temozolomide-mediated DNA methylation in human myeloid precursor cells: differential involvement of intrinsic and extrinsic apoptotic pathways. Clin Cancer Res. 2013;19(10):2699-2709. doi:10.1158/1078-0432.CCR-12-2671

7. Rizzuto R, De Stefani D, Raffaello A, Mammucari C. Mitochondria as sensors and regulators of calcium signalling. Nat Rev Mol Cell Biol. 2012;13(9):566-578. doi:10.1038/nrm3412

8. Wu-Wong JR, Chiou WJ, Hoffman DJ, Winn M, von Geldern TW, Opgenorth TJ. Endothelins and endothelin receptor antagonists: binding to plasma proteins. Life Sci. 1996;58(21):1839-1847. doi:10.1016/0024-3205(96)00168-3

9. Woodward MN, Sidebotham EL, Connell MG, et al. Analysis of the effects of endothelin- 3 on the development of neural crest cells in the embryonic mouse gut. J Pediatr Surg. 2003;38(9):1322-1328. doi:10.1016/s0022-3468(03)00389-0

10. Cui L, Wong EH, Cheng G, et al. Genetic analyses of a three generation family segregating hirschsprung disease and iris heterochromia. PLoS One. 2013;8(6):e66631. doi:10.1371/journal.pone.0066631

11. Loftus SK, Chen Y, Gooden G, et al. Informatic selection of a neural crest-melanocyte cDNA set for microarray analysis. Proc Natl Acad Sci U S A. 1999;96(16):9277-9280. doi:10.1073/pnas.96.16.9277

12. Bagnato A, Rosano L, Spinella F, Di Castro V, Tecce R, Natali PG. Endothelin B receptor blockade inhibits dynamics of cell interactions and communications in melanoma cell progression. Cancer Res. 2004;64(4):1436-1443.
13. Demunter A, De Wolf-Peeters C, Degreef H, Stas M, van den Oord JJ. Expression of the endothelin-B receptor in pigment cell lesions of the skin. Evidence for its role as tumor progression marker in malignant melanoma. Virchows Arch. 2001;438(5):485-491.

14. Lahav R, Heffner G, Patterson PH. An endothelin receptor B antagonist inhibits growth and induces cell death in human melanoma cells in vitro and in vivo. Proc Natl Acad Sci U S A. 1999;96(20):1149611500. doi:10.1073/pnas.96.20.11496

15. Asundi J, Reed C, Arca J, et al. An antibody-drug conjugate targeting the endothelin B receptor for the treatment of melanoma. Clin Cancer Res. 2011;17(5):965-975. doi:10.1158/1078-0432.CCR-10-2340

16. Lahav R, Suva ML, Rimoldi D, Patterson PH, Stamenkovic I. Endothelin receptor $\mathrm{B}$ inhibition triggers apoptosis and enhances angiogenesis in melanomas. Cancer Res. 2004;64(24):8945-8953. doi:10.1158/0008-5472.CAN-04-1510

17. Okazawa M, Shiraki T, Ninomiya H, Kobayashi S, Masaki T. Endothelin-induced apoptosis of A375 human melanoma cells. $J$ Biol Chem. 1998;273(20):12584-12592. doi:10.1074/ jbc. 273.20 .12584

18. Wouters J, Hunger RE, Garrod T, et al. First-in-human proof-ofconcept study: intralesional administration of BQ788, an endothelin receptor B antagonist, to melanoma skin metastases. Oncologist. 2015;20(10):1121-1122. doi:10.1634/theoncologist.2015-0139

19. Kefford RF, Clingan PR, Brady B, Ballmer A, Morganti A, Hersey P. A randomized, double-blind, placebo-controlled study of high-dose bosentan in patients with stage IV metastatic melanoma receiving first-line dacarbazine chemotherapy. Mol Cancer. 2010;9:69. doi:10.1186/1476-4598-9-254

20. Kefford R, Beith JM, Van Hazel GA, et al. A phase II study of bosentan, a dual endothelin receptor antagonist, as monotherapy in patients with stage IV metastatic melanoma. Invest New Drugs. 2007;25(3):247-252. doi:10.1007/s10637-006-9014-7

21. Shyamala V, Moulthrop TH, Stratton-Thomas J, Tekamp-Olson P. Two distinct human endothelin $\mathrm{B}$ receptors generated by alternative splicing from a single gene. Cell Mol Biol Res. 1994;40 (4):285-296.

22. Nakamuta M, Takayanagi R, Sakai $Y$, et al. Cloning and sequence analysis of a cDNA encoding human non-selective type of endothelin receptor. Biochem Biophys Res Commun. 1991;177(1):34-39. doi:10.1016/0006291x(91)91944-8

23. Elshourbagy NA, Adamou JE, Gagnon AW, Wu HL, Pullen M, Nambi P. Molecular characterization of a novel human endothelin receptor splice variant. J Biol Chem. 1996;271(41):25300-25307. doi:10.1074/jbc.271.41.25300

24. Tsutsumi M, Liang G, Jones PA. Novel endothelin B receptor transcripts with the potential of generating a new receptor. Gene. 1999;228(1-2):43-49. doi:10.1016/s0378-1119(99)00014-1

25. Gakh O, Cavadini P, Isaya G. Mitochondrial processing peptidases. Biochim Biophys Acta. 2002;1592(1):63-77. doi:10.1016/s0167-4889 (02)00265-3

26. Claros MG. MitoProt, a Macintosh application for studying mitochondrial proteins. Comput Appl Biosci. 1995;11(4):441-447.

27. Emanuelsson O, Brunak S, von Heijne G, Nielsen H. Locating proteins in the cell using TargetP, SignalP and related tools. Nat Protoc. 2007;2(4):953-971. doi:10.1038/nprot.2007.131

28. MacGowan GA, Du C, Glonty V, Suhan JP, Koretsky AP, Farkas DL. Rhod-2 based measurements of intracellular calcium in the perfused mouse heart: cellular and subcellular localization and response to positive inotropy. J Biomed Opt. 2001;6(1):23-30. doi:10.1117/ 1.1316091

29. Scharfe C, Zaccaria P, Hoertnagel K, et al. MITOP: database for mitochondria-related proteins, genes and diseases. Nucleic Acids Res. 1999;27(1):153-155. doi:10.1093/nar/27.1.153

30. McGuffin LJ, Bryson K, Jones DT. The PSIPRED protein structure prediction server. Bioinformatics. 2000;16(4):404-405. doi:10.1093/ bioinformatics/16.4.404 
31. Pradhan RK, Qi F, Beard DA, Dash RK. Characterization of membrane potential dependency of mitochondrial $\mathrm{Ca}^{2+}$ uptake by an improved biophysical model of mitochondrial $\mathrm{Ca}^{2+}$ uniporter. PLoS One. 2010;5(10):e13278. doi:10.1371/journal.pone.0013278

32. Trollinger DR, Cascio WE, Lemasters JJ. Selective loading of Rhod 2 into mitochondria shows mitochondrial $\mathrm{Ca}^{2+}$ transients during the contractile cycle in adult rabbit cardiac myocytes. Biochem Biophys Res Commun. 1997;236(3):738-742. doi:10.1006/bbrc.1997.7042

33. Cox ML, Meek DW. Phosphorylation of serine 392 in p53 is a common and integral event during p53 induction by diverse stimuli. Cell Signal. 2010;22(3):564-571. doi:10.1016/j.cellsig.2009.11.014

34. Sakaguchi K, Sakamoto H, Lewis MS, et al. Phosphorylation of serine 392 stabilizes the tetramer formation of tumor suppressor protein p53. Biochemistry. 1997;36(33):10117-10124. doi:10.1021/ bi970759w

35. Altenhofer S, Witte I, Teiber JF, et al. One enzyme, two functions: PON2 prevents mitochondrial superoxide formation and apoptosis independent from its lactonase activity. J Biol Chem. 2010;285 (32):24398-24403. doi:10.1074/jbc.M110.118604

36. Kochl R, Alken M, Rutz C, et al. The signal peptide of the G proteincoupled human endothelin $\mathrm{B}$ receptor is necessary for translocation of the $\mathrm{N}$-terminal tail across the endoplasmic reticulum membrane. $J$ Biol Chem. 2002;277(18):16131-16138. doi:10.1074/jbc.M111674200

37. Andreeva AV, Kutuzov MA, Voyno-Yasenetskaya TA. G alpha12 is targeted to the mitochondria and affects mitochondrial morphology and motility. Faseb J. 2008;22(8):2821-2831. doi:10.1096/fj.07104224

38. Lyssand JS, Bajjalieh SM. The heterotrimeric [corrected] G protein subunit $\mathrm{G}$ alpha $\mathrm{i}$ is present on mitochondria. FEBS Lett. 2007;581 (30):5765-5768. doi:10.1016/j.febslet.2007.11.044

39. Beninca C, Planaguma J, de Freitas Shuck A, et al. A new noncanonical pathway of Galpha(q) protein regulating mitochondrial dynamics and bioenergetics. Cell Signal. 2014;26(5):1135-1146. doi:10.1016/j.cellsig.2014.01.009

40. Heijne G. The distribution of positively charged residues in bacterial inner membrane proteins correlates with the trans-membrane topology. EMBO J. 1986;5(11):3021-3027.

41. Oksche A, Boese G, Horstmeyer A, et al. Late endosomal/lysosomal targeting and lack of recycling of the ligand-occupied endothelin B receptor. Mol Pharmacol. 2000;57(6):1104-1113.

42. Grantcharova E, Furkert J, Reusch HP, et al. The extracellular N terminus of the endothelin B (ETB) receptor is cleaved by a metalloprotease in an agonist-dependent process. $J$ Biol Chem. 2002;277 (46):43933-43941. doi:10.1074/jbc.M208407200

43. Hagiwara H, Kozuka M, Sakaguchi H, Eguchi S, Ito T, Hirose S. Separation and purification of 34- and 52-kDa species of bovine lung endothelin receptors and identification of the 34-kDa species as a degradation product. J Cardiovasc Pharmacol. 1991;17(Suppl 7):S117-S118.

44. Chacinska A, Koehler CM, Milenkovic D, Lithgow T, Pfanner N. Importing mitochondrial proteins: machineries and mechanisms. Cell. 2009;138(4):628-644. doi:10.1016/j.cell.2009.08.005

45. Sanchez-Mejias A, Fernandez RM, Lopez-Alonso M, Antinolo G, Borrego S. New roles of EDNRB and EDN3 in the pathogenesis of Hirschsprung disease. Genet Med. 2010;12(1):39-43. doi:10.1097/ GIM.0b013e3181c371b0

46. Zhang Y, Qian Y, Lu W, Chen X. The G protein-coupled receptor 87 is necessary for p53-dependent cell survival in response to genotoxic stress. Cancer Res. 2009;69(15):6049-6056. doi:10.1158/0008-5472. CAN-09-0621
47. Kimura M, Mizukami Y, Miura T, Fujimoto K, Kobayashi S, Matsuzaki M. Orphan G protein-coupled receptor, GPR41, induces apoptosis via a p53/Bax pathway during ischemic hypoxia and reoxygenation. J Biol Chem. 2001;276(28):26453-26460. doi:10.1074/ jbc.M101289200

48. Costantini P, Bruey JM, Castedo M, et al. Pre-processed caspase-9 contained in mitochondria participates in apoptosis. Cell Death Differ. 2002;9(1):82-88. doi:10.1038/sj.cdd.4400932

49. La Piana G, Fransvea E, Marzulli D, Lofrumento NE. Mitochondrial membrane potential supported by exogenous cytochrome c oxidation mimics the early stages of apoptosis. Biochem Biophys Res Commun. 1998;246(2):556-561. doi:10.1006/bbrc. 1998.8664

50. Lappano R, Maggiolini M. G protein-coupled receptors: novel targets for drug discovery in cancer. Nat Rev Drug Discov. 2011;10(1):4760. doi: $10.1038 / \mathrm{nrd} 3320$

51. Lahav R. Endothelin receptor B is required for the expansion of melanocyte precursors and malignant melanoma. Int J Dev Biol. 2005;49(2-3):173-180. doi:10.1387/ijdb.041951rl

52. Turner PR, Mefford S, Christakos S, Nissenson RA. Apoptosis mediated by activation of the $\mathrm{G}$ protein-coupled receptor for parathyroid hormone (PTH)/PTH-related protein (PTHrP). Mol Endocrinol. 2000;14(2):241-254. doi:10.1210/mend.14.2.0417

53. Hawkins BJ, Solt LA, Chowdhury I, et al. G protein-coupled receptor $\mathrm{Ca} 2+$-linked mitochondrial reactive oxygen species are essential for endothelial/leukocyte adherence. Mol Cell Biol. 2007;27(21):75827593. doi:10.1128/MCB.00493-07

54. Starkov AA. Measurement of mitochondrial ROS production. Methods Mol Biol. 2010;648:245-255. doi:10.1007/978-1-60761756-3 16

55. Hansson MJ, Mansson R, Morota S, et al. Calcium-induced generation of reactive oxygen species in brain mitochondria is mediated by permeability transition. Free Radic Biol Med. 2008;45(3):284-294. doi:10.1016/j.freeradbiomed.2008.04.021

56. Belyaeva EA. Mitochondrial respiratory chain inhibitors modulate the metal-induced inner mitochondrial membrane permeabilization. Acta Biochim Pol. 2010;57(4):435-441.

57. Votyakova TV, Reynolds IJ. Ca2+-induced permeabilization promotes free radical release from rat brain mitochondria with partially inhibited complex I. J Neurochem. 2005;93(3):526-537. doi:10.1111/ j.1471-4159.2005.03042.x

58. Gyulkhandanyan AV, Pennefather PS. Shift in the localization of sites of hydrogen peroxide production in brain mitochondria by mitochondrial stress. J Neurochem. 2004;90(2):405-421. doi:10.1111/j.14714159.2004.02489.x

59. Starkov AA, Polster BM, Fiskum G. Regulation of hydrogen peroxide production by brain mitochondria by calcium and Bax. $J$ Neurochem. 2002;83(1):220-228. doi:10.1046/j.1471-4159.2002.01 153.x

60. Solyakov L, Sayan E, Riley J, Pointon A, Tobin AB. Regulation of p53 expression, phosphorylation and subcellular localization by a Gprotein-coupled receptor. Oncogene. 2009;28(41):3619-3630. doi:10. 1038/onc.2009.225

61. Costa LG, de Laat R, Dao K, Pellacani C, Cole TB, Furlong CE. Paraoxonase-2 (PON2) in brain and its potential role in neuroprotection. Neurotoxicology. 2014;43:3-9. doi:10.1016/j.neuro.2013.08.011

62. Devarajan A, Bourquard N, Hama S, et al. Paraoxonase 2 deficiency alters mitochondrial function and exacerbates the development of atherosclerosis. Antioxid Redox Signal. 2011;14(3):341-351. doi:10. 1089/ars.2010.3430 


\section{Supplementary material}

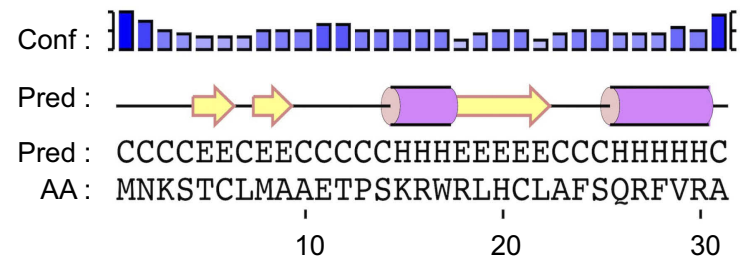

\begin{tabular}{|c|c|c|}
\hline Legend & & \\
\hline$\Rightarrow$ & $\begin{array}{l}=\text { Helix } \\
=\text { Strand }\end{array}$ & 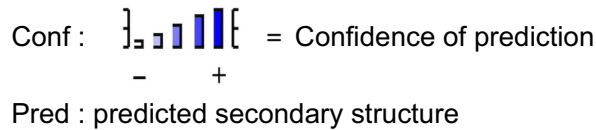 \\
\hline & $=$ Coil & $\mathrm{AA}$ : target sequence \\
\hline
\end{tabular}

Figure SI Secondary structure of the N-terminal region of EDNRB isoform 3 was predicted by the PSIPRED server.

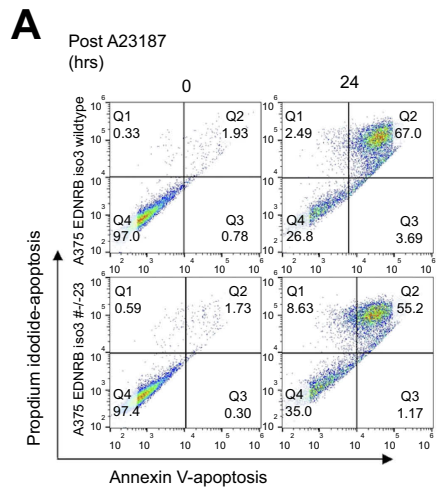

B

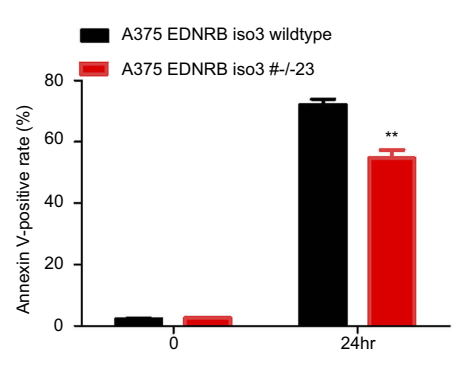

C

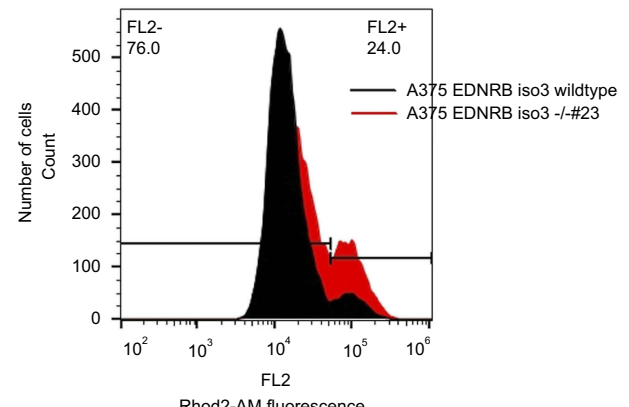

Figure S2 Depletion of EDNRB isoform 3 confers resistance to $A 23$ I87. (A) Apoptosis was analyzed by flow cytometry after annexin $V$ and propidium iodide staining. Cells were incubated with and without A23I87 (I0 $\mu \mathrm{M})$ for $24 \mathrm{hrs}$. (B) Total apoptosis is the sum of the percentage of annexin $\mathrm{V}$ only and annexin $\mathrm{V} /$ propidium iodide stained cells. Data represent as mean \pm SD from three independent experiments. ${ }^{* *} p<0.01$. (C) Representative flow cytometry histograms indicating Rhod2-AM staining signals of EDNRB isoform 3-depleted and control A375 cells after treated with $10 \mu \mathrm{M}$ A23। 87 for 24 hrs. Rhod 2 fluorescence intensity was monitored by flow cytometry. 


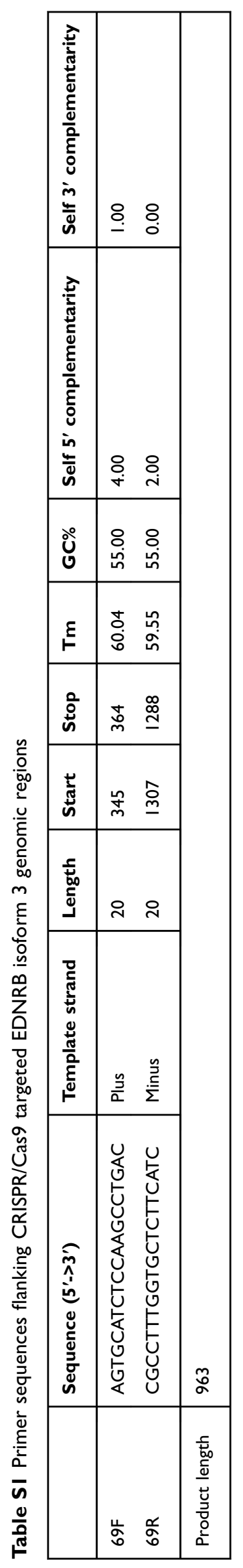




\section{Publish your work in this journal}

Cancer Management and Research is an international, peer-reviewed open access journal focusing on cancer research and the optimal use of preventative and integrated treatment interventions to achieve improved outcomes, enhanced survival and quality of life for the cancer patient.
The manuscript management system is completely online and includes a very quick and fair peer-review system, which is all easy to use. Visit http://www.dovepress.com/testimonials.php to read real quotes from published authors.

Submit your manuscript here: https://www.dovepress.com/cancer-management-and-research-journal 